\title{
42. Fortbildungskongress für ärztliches Assistenzpersonal in der Radiologie - "Lebkuchenkongress“ - ein Rückblick
}

\author{
Zweites Adventswochenende in Franken. Es ist kalt in Fürth. \\ Es liegt Schnee, die Straßen sind glatt. Doch ist dies kein Hinde- \\ rungsgrund für über 430 MTRA aus ganz Deutschland den \\ schon traditionellen „Lebkuchenkongress“ zu besuchen.
}

Nun bereits zum dritten Mal im schönen Hotel Pyramide beheimatet, traten die Teilnehmer in ein vorweihnachtliches geschmücktes Foyer, wo heißer Kaffee bereits auf sie wartete. Und die Fahrt hat sich gelohnt: Erneut hat es die Vereinigung der Medizinisch-Technischen Berufe in der Deutschen Röntgengesellschaft (VMTB) verstanden, ein hochinteressantes Programm auf die Beine zu stellen. Im Bereich Röntgendiagnostik ging es dieses Jahr schwerpunktmäßig um die Onkologie. Die Strahlentherapie informierte über neue Entwicklungen beim Mammakarzinom und hier war das Interesse so groß, dass in einen größeren Raum gewechselt werden musste. Von der Durchführung einer Hirnrezeptorszintigrafie bis zum Amyloid-PET informierte das Programm der Nuklearmedizin.

Früh ausgebucht waren erneut die neun Klinikseminare, welche in den Kliniken Nürnberg Nord und Süd stattfanden. Dank des extra dafür von der VMTB eingerichteten kostenfreien Shuttlebus-Services



Voll besetzter Raum in der Röntgendiagnostik.

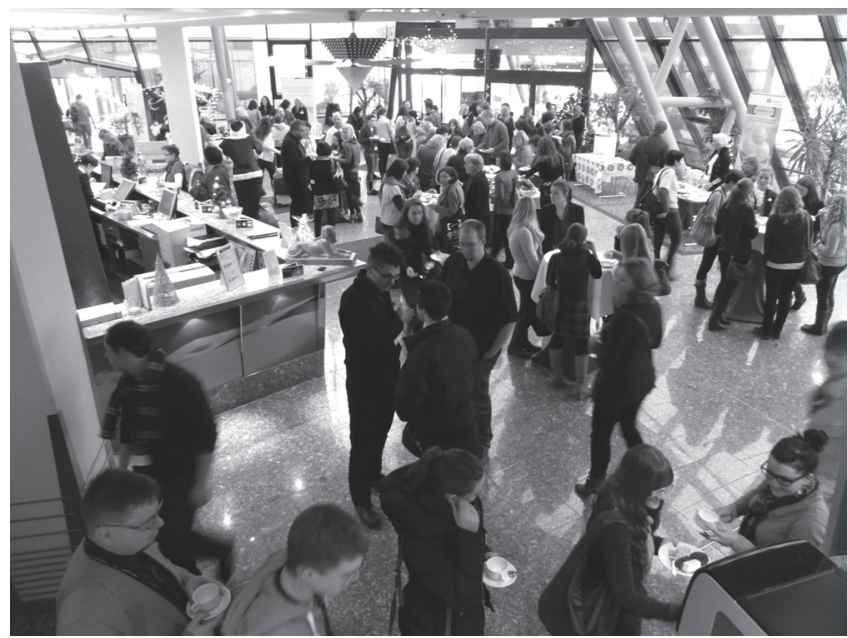

Die schöne Atmosphäre des Hotels Pyramide begeisterte erneut die Teilnehmer. 
konnten die Teilnehmer auch hier den winterlichen Straßenverhältnissen trotzen und alle kamen gut und pünktlich hin und wieder zurück zur Pyramide.

Die Möglichkeit zur Fachkundeaktualisierung nach RöV und StrSchV war auch 2012 wieder möglich und wurde von vielen Teilnehmern rege genutzt. In den Pausen konnte man sich bei zahlreichen süßen und herzhaften Leckereien für das weitere Programm stärken.

Zum ersten Mal gab es in diesem Jahr ein eigenes MTRA-Schüler-Programm. Über 85 Schüler aus Nürnberg, Erlangen, Würzburg, Regensburg und Kempten hörten spannende Vorträge über die Grundlagen der CT und der MRT, lernten Wissenswertes über nonverbale Kommunikation sowie die Durchführung einer PET-CT-Untersuchung. Alle Teilnehmer waren voll des Lobes.

Ebenfalls zum ersten Mal hatten die Teilnehmer die Möglichkeit am Freitagabend nach getaner Arbeit mit einem Shuttlebus direkt von der Pyramide zum berühmten Nürnberger Christkindelsmarkt zu fahren. Dieses kostenfreie Angebot nahmen dann auch über 80 Teilnehmer wahr und freuten sich auf leckeren Glühwein und Nürnberger Lebkuchen.

Die VMTB möchte sich sehr herzlich bei dem Organisationsteam, dem Klinikum Nürnberg, allen Referenten und der Industrie für diese sehr gelungene Ver- anstaltung bedanken. Und natürlich gilt der Dank auch ganz besonders Ihnen als Teilnehmer.

Wir freuen uns schon jetzt, Sie am 6. und 7. Dezember 2013 zum 43. Fortbildungskongress für ärztliches Assistenzpersonal in der Radiologie begrüßen zu dürfen.
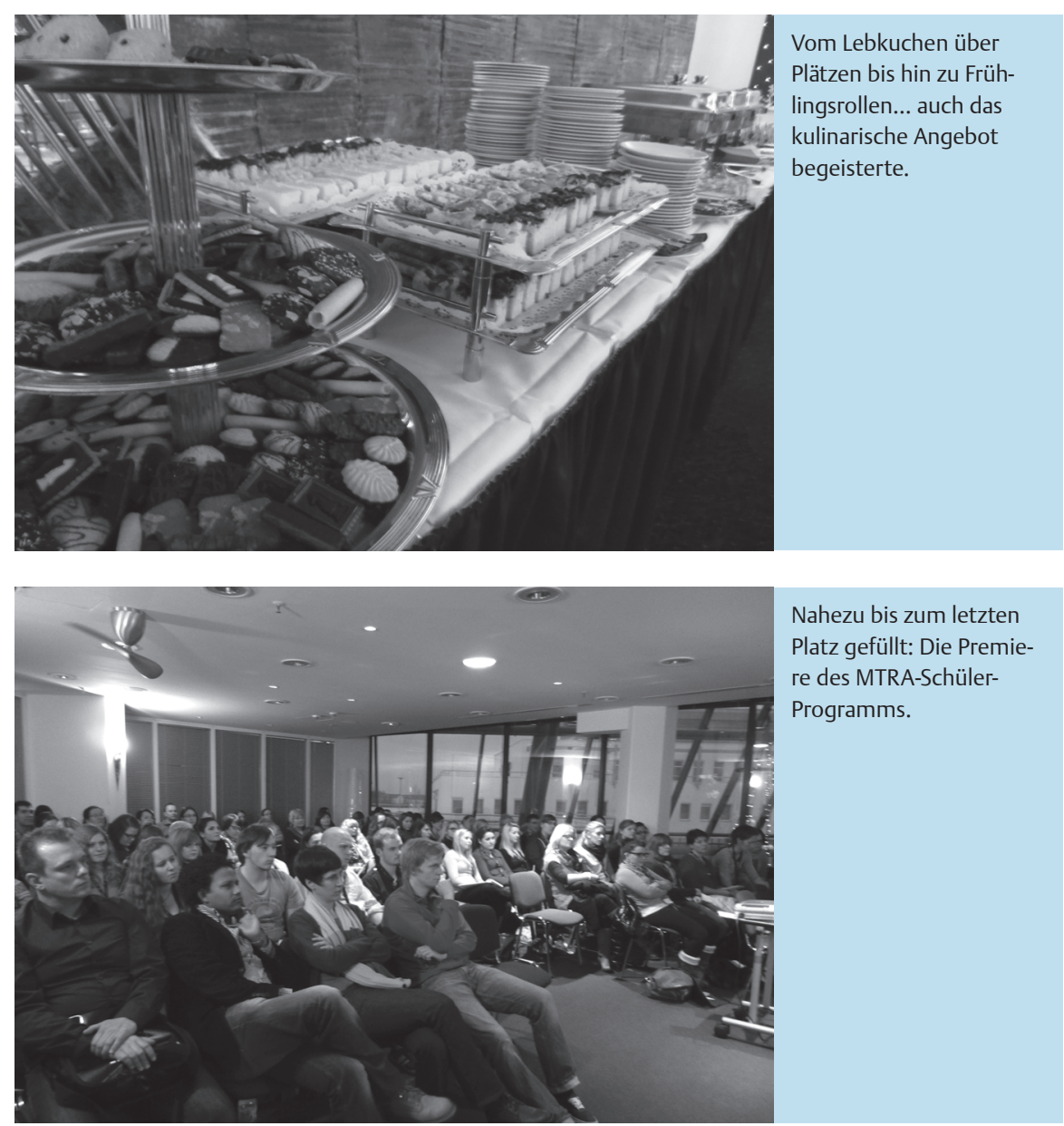

Nahezu bis zum letzten Platz gefüllt: Die Premiere des MTRA-SchülerProgramms. 